\title{
FAKTOR-FAKTOR YANG MEMPENGARUHI KEPUTUSAN KONSUMEN UNTUK BERKUNJUNG KE WISATA ALAM WATERBOM DESA JANJI
}

\author{
SITI LAM'AH NASUTION
}

Dosen Tetap Sekolah Tinggi Ilmu Ekonomi (STIE) Labuhan Batu

\begin{abstract}
ABSTRAK
Tujuan dari penelitian ini adalah untuk mengetahui pengaruh produk, harga, lokasi dan promosi wisata terhadap keputusan berkunjung ke wisata alam Waterboom Desa Janji. Pengumpulan datamenggunakan wawancara, kuesioner dan studi pustaka. Pengerjaan metodeanalisis data dengan menggunakan bantuan software SPSS 20.0 for Windows.Data yang digunakan adalah data primer dan sekunder. Penelitian inimenggunakan 93 responden sebagai sampel penelitian yang diambil denganmenggunakan teknik purposive sampling yaitu sampel yang dipilih dengan pertimbangan tertentu.

Hasil penelitian berdasarkan uji secara serempak (uji $F$ ) menunjukkan bahwa secara simultan (serempak) produk, harga, lokasi, dan promosiberpengaruh positif dansignifikan terhadap keputusan berkunjung ke wisata alam Waterboom Desa Janji dan harga adalah variabel paling dominan. Hasil pengujian hipotesis secara parsial (uji t) menunjukkan bahwa produk $\left(X_{1}\right)$, harga $\left(X_{2}\right)$, dan lokasi $\left(X_{3}\right)$ berpengaruh positif dan signifikan terhadap keputusan berkunjung ke wisata alam Waterboom Desa Janji, sedangkan promosi $\left(X_{4}\right)$ berpengaruh positif tetapi tidak signifikan terhadap keputusan berkunjung ke wisata alam Waterboom Desa Janji.Berdasarkan hasil uji determinasi diketahui bahwa keputusan berkunjung dapat dijelaskan oleh variabel produk, harga, lokasi, dan promosi sebesar 58,1\%. Sedangkan sisanya 41,9\% dapat dijelaskan oleh variabel lain yang tidak dibahas dalam penelitian ini.
\end{abstract}

Kata kunci : Produk, Harga, Lokasi, Promosi, Keputusan berkunjung.

\section{PENDAHULUAN}

Pariwisata adalah suatu aktivitas manusia yang dilakukan secara sadaryang mendapat pelayanan secara bergantian diantara orang-orang dalam suatunegara itu sendiri/ di luar negeri, meliputi pendiaman orang-orang dari daerah lainuntuk sementara waktu mencari kepuasan yang beraneka-ragam dan berbedadengan apa yang dialaminya. Industri pariwisata saat ini dianggap sebagaiindustri yang paling pesat perkembangannya. Hal ini dapat dilihat dari semakinmeningkatnya jumlah pengunjung yang datang ke wahana-wahana wisata.Jika mempunyai penghasilan lebih dan waktu yang luang, orang akancenderungmelakukan perjalanan untuk berwisata keluar daerah asal mereka.Mengunjungitempat wisata di daerah sendiri juga merupakan hal yangmenyenangkan danmenjadi kegiatan yang digemari oleh masyarakat dan menjadi kebutuhanmasyarakat. Wisata keluarga merupakan hal yang menjadi daya tarikbagi setiapkeluarga pada masa liburan.

Wisata keluargaWaterboom Janji yang terletak di Desa Janji Kecamatan Bilah Barat Kabupaten Labuhanbatu adalah salah satu tempat wisata rekreasi dan atraksibermain yang ada diRantauprapat. Waterboom Janji sudah banyak dipilih oleh wargamasyarakat sebagai tempat wisata keluarga. Dengan konsep Watertaintment menyajikanprogram-program acara 
hiburan yang akan memberikan kemudahan kepadapengunjung dalam berlibur bersama keluarga, teman dan relasi.

Salah satu cara untuk dapat merebut hati pengunjung agar tertarik untukberkunjung adalah dengan cara menerapkan strategi pemasaran yang salah satuelemennya adalah dengan bauran pemasaran. Bauran Pemasaran adalah kumpulanalat pemasaran taktis terkendali yang dipadukan perusahaan untuk menghasilkanrespons yang diinginkan di pasar sasaran (Kotler dan Amstrong, 2008:62). Bauranpemasaran terdiri dari semua hal yang dapat dilakukan perusahaan untukmempengaruhi permintaan produknya. Berbagai kemungkinan ini dapatdikelompokkan menjadi empat kelompok variabel yang disebut "empat P" :Product, Price, Place dan Promotion. Faktor produk, harga, lokasi dan promosiadalah merupakan faktor penting di dalam bauran pemasaran. Demikian halnyadalam penerapan strategi yang dilakukan oleh perusahaan jasa di dalam jugasenantiasa menerapkan pengembangan daripada strategi harga, lokasi dan promosiyang tepat agar dapat menarik minat konsumen untuk berkunjung ke daerahwisata tersebut.

\section{TIN JAUAN PUSTAKA}

Produk merupakan barang atau jasa yang digunakan untuk memuaskankebutuhan konsumen dan produk dapat mempunyai bentuk, atau dapat berupa jasatanpa bentuk fisik (Scarborough, 2008:413). Para konsumen, pada kenyataannyamembeli lebih dari sekedar sifat-sifat fisik yang melekat pada barang tersebut,mereka membeli pemuas kebutuhan dalam bentuk manfaat produk yang dibelinya.

Harga produk atau jasa adalah faktor kunci dalam keputusan pembelian.Menurut Scarborough (2008:417) harga mempengaruhi baik penjualan maupunlaba, dan tanpa harga yang benar, penjualan dan laba akan mendapatkan kesulitan.

Harga yang benar untuk produk atau jasa bergantung pada tiga faktor,yaitu:struktur biaya perusahaan, penilaian mengenai pasar, dan citra pasar yang ingindibentuk dalam pikiran pelanggan.

Lokasi/tempat usaha menjadi semakin penting karena pelanggan semakinmengharapkan layanan dan kenyamanan yang semakin memuaskan (Scarborough,2008:415). Tata letak, dekorasi, lingkungan sekitar dapat menimbulkan kesansuasana dari penampilan suatu tempat. Suasana dapat menciptakan perasaan santaiataupun sibuk, kesan mewah ataupun efisiensi, sikap ramah ataupun sikap dingin, teroganisir atupun kacau, atau suasana hati menyenangkan.

Promosi menyangkut baik periklanan maupun penjualan secara pribadi.Promosi bertujuan untuk menginformasikan dan membujuk pelanggan. Dimana iklan mengkomunikasikan manfaat barang atau jasa kepada calon pelanggan melalui media massa dan penjualan secara pribadi melibatkan seni membujuk dalam penjualan dengan dasar tatap muka. Program promosi perusahaan kecil bisaberperan penting dalam menciptakan citra tertentu dalam pikiran pelanggan,apakah untuk kalangan atas, potongan harga, atau diantara keduanya(Scarborough, 2008:418).

Keputusan berkunjung dari konsumen sangat dipengaruhi oleh gaya hidup dan marketing mix yang dikenal dengan $4 \mathrm{P}$ yaitu :product, price, place, dan promotion yangdilakukan oleh pihak perusahaan. Dalam penelitian ini empat faktor tersebut yangperlu dipertimbangkan dalam melakukan kunjungan. Berdasarkan hal tersebut maka secara sederhana kerangkakonseptual penelitian ini dapat digambarkan sebagai berikut : 


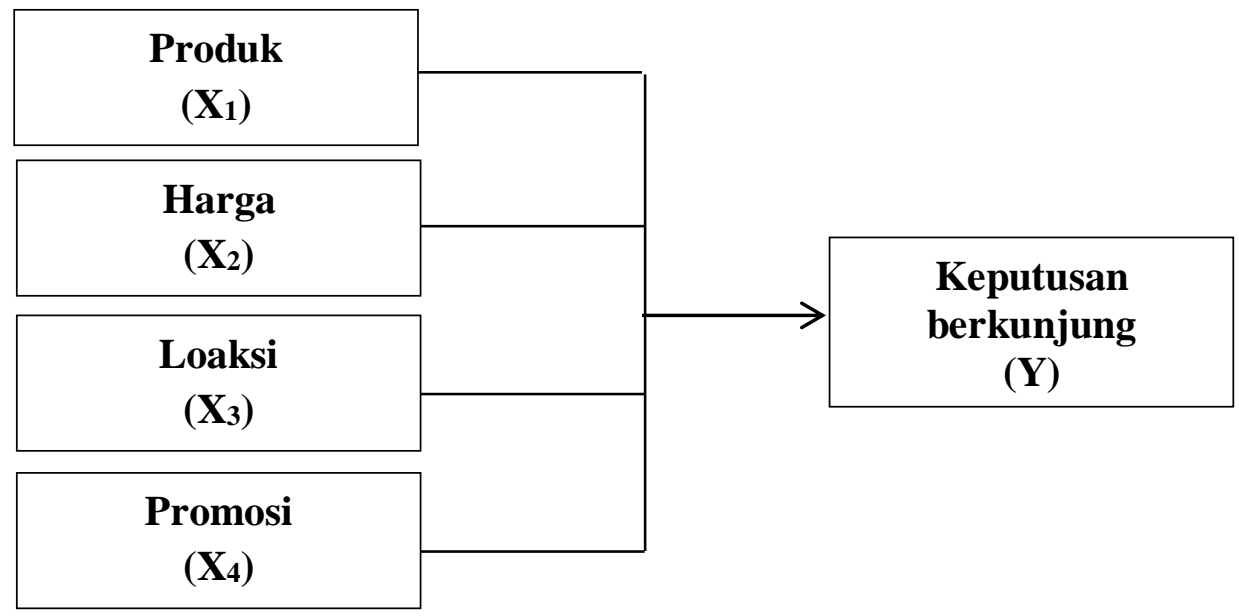

Hipotesis merupakan jawaban yang sifatnya sementara berdasarkan rumusan masalah yang kebenarannya akan diuji dalam pengujian hipotesis(Sugiyono, 2008:306). Berdasarkan perumusan masalah yang ada, maka hipotesis penelitian dirumuskan sebagi berikut :

1. Produkberpengaruh positif dan signifikan terhadap keputusan berkunjung ke Wisata Alam Waterboom Desa Janji.

2. Harga berpengaruh positif dan signifikan terhadap keputusan berkunjung ke Wisata Alam Waterboom Desa Janji.

3. Lokasi berpengaruh positif dan signifikan terhadap keputusan berkunjung ke Wisata Alam Waterboom Desa Janji.

4. Promosi berpengaruh positif dan signifikan terhadap keputusan berkunjung ke Wisata Alam Waterboom Desa Janji.

5. Produk, Harga, Lokasi, dan Promosi berpengaruh positif dan signifikan terhadap keputusan berkunjung ke Wisata Alam Waterboom Desa Janji.

\section{METODE PENELITIAN}

\section{A. Populasi dan Sampel}

Populasi adalah suatu kelompok dari elemen penelitian, dimanaelemen unit terkecil yang merupakan sumber dari data yang diperlukan(Situmorang, dkk, 2008:128). Populasi dalam penelitian ini adalah rata-rataseluruh pengunjung Waterboom Desa Janji pada tahun 2015 yang berjumlah 1344 orang pengunjungperbulan.

Sampel adalah suatu bagian dari sampel yang akan diteliti dandianggap yang dapat menggambarkan populasinya (Situmorang, dkk,2008:151). Penelitian ini menggunakan teknik purposive sampling yaitusampel yang dipilih dengan pertimbangan tertentu (Sugiyono, 2008:78). Ukuransampel ditentukan dengan menggunakan rumus Slovin (Umar, 2006:78) yaitutehnik pengambilan sampel dimana peneliti menggunakan sampel dari populasidengan rumus :

$n=\frac{N}{\left(1+N e^{2}\right)}$

Keterangan :

$\mathrm{n}=$ jumlah sampel

$\mathrm{N}=$ ukuran populasi

$e=$ margin error $(10 \%$ atau 0,1$)$

Sehingga Jumlah Sampel (n) menjadi : 


$$
\begin{aligned}
& n=\frac{1344}{\left(1+1344(0,1)^{2}\right)} \\
& n=93,33 \approx 93 \text { orang. }
\end{aligned}
$$

\section{B. Teknik Pengumpulan Data}

Adapun teknik pengumpulan data dalam penelitian ini yaitu :

1. Observasi yaitu dengan melakukan pengamatan langsung pada objekpenelitianuntuk mendapatkan data yang aktual.

2. Wawancara yaitu dengan melakukan tanya jawab atau wawancara secaralangsung dengan pihak-pihak yang terkait dengan objek penelitian untukmendapatkan informasi.

3. Kuesioner yaitu dengan menyebarkan daftar pertanyaan kepada sampelterpilih.

\section{Metode Analisis Data}

\section{Metode Analisis Deskriptif}

Analisis deskriptif adalah kegiatan mengelompokkan, memisahkan,mengatur, mengurutkan, menganalisis serta menyimpulkan data sehinggahasilnya dapat ditafsirkan dan memberikan informasi deskriptif untuk menjawab pertanyaan dari defenisi masalah.

\section{Metode Analisis Statistik}

Metode analisis Statistik yang digunakan adalah :

\section{a. Uji Asumsi Klasik}

Uji asumsi klasik dilakukan sebelum melakukan analisis regresi, agardapat diperkirakan yang tidak bias dan efesiensi maka dilakukan pengujian asumsiklasik yang harus dipenuhi, yaitu :

1) Uji Normalitas

Uji normalitas dilakukan untuk menguji apakah dalam model regresi, variabel bebas dan variabel terikat atau keduanya telah terdistribusi secara normal atau tidak. Model regresi yang baik adalah model yang memiliki distribusi normal atau mendekati normal. Normalitas dapat dideteksi dengan melihat penyebaran data (titik) dari sumbu diagonal dari grafik atau melihat histogram dari residualnya.Uji normalitas juga dapat dilakukan dengan menggunakan pendekatan Kolmogrov-Smirnov. Dengan menggunakan tingkat signifikansi 5\% maka jika nilai Asymp.sig (2-tailed) diatas nilai signifikansi 5\% artinya variabel residual berdistribusi normal.

2) Uji Multikoliniearitas

Adanya hubungan linier yang sempurna diantara variabel-variabel bebasdalam model regresi. Untuk mengetahui ada atau tidaknya gejalamultikolinearitas dapat dilihat dari besarnya Tolerance Value danVariance Inflation Faktor (VIF). Batas Tolerance Value adalah 0,1 dan batas VIFadalah 5 (Situmorang, dkk, 2008:137), di mana:

- Tolerance value $<0,1$ atau VIF $>5=$ terjadi multikolinearitas

- Tolerance value $>0,1$ atau $\mathrm{VIF}<5=$ tidak terjadi multikolinearitas.

3) Uji Heteroskedastisitas

Situmorang dkk (2008:122) menyatakan bahwa uji heteroskedastisitas pada prinsipnya juga ingin menguji apakah sebuah grup mempunyai varians yang sama diantara anggota grup tersebut.Jika varians sama, dan ini yang seharusnya terjadi maka dikatakan ada homoskedastisitas. Sedangkan jika varians tidak sama dikatan terjadi heterokedastisitas.

Model regresi yang baik adalah bila tidak terjadi heteroskedastisitas. Cara yang dapat dilakukan untuk mendeteksi heteroskedastisitas adalah melihat grafik scatterplot antara nilai prediksi (*ZPRED) dengan nilai residualnya (*ZRESID). *ZPRED dan *ZRESID merupakan nilai prediksi dan residual yang telah distandarisasi. Nilainya memang 
berubah, tetapi skalanya tidak,sehingga tetap mencerminkan data sesungguhnya (Usman dan Sobari, 2013:78). Indikasi terjadinya heterosdekastisitas dapat dilihat bila terjadi pola sistematik tertentu pada plot seperti titik-titik yang membentuk pola yang teratur, namun bila tidak terdapat pola yang jelas serta titik-titik nya menyebar maka bisa diindikasikan model regresi bebas dari heterosdekastisitas.

Gejala heteroskedastisitas juga dapat diujidengan menggunakan uji Glejser dengan pengambilan keputusan jika variabelindependen signifikan secara statistik mempengaruhi variabel dependen, makaada indikasi terjadinya heteroskedastisitas. Jika probabilitas signifikannyadiatas 5\% $(>0,05)$ dapat disimpulkan model regrasi tidakmengarah adanya heteroskedastisitas.

\section{b. Analisis Regresi Linear Berganda}

Analisis regresi linear berganda digunakan untuk menganalisis seberapa besar pengaruh dan hubungan antara variabel bebas dengan variabel terikat. Analisis regresi berganda digunakan karena jumlah variabel bebas yang akan diteliti berjumlah lebih dari satu variabel. Dalam penelitian ini peneliti menggunakan aplikasi SPSS 20.0 for Windows untuk menghitung model regresi berganda ini. Rumus matematisnya adalah :

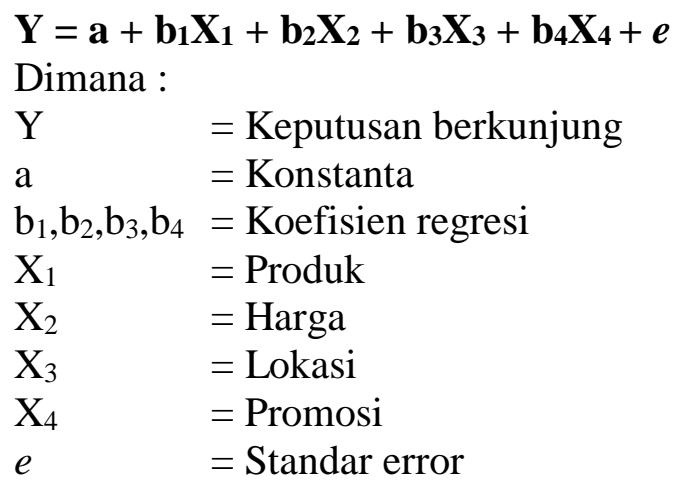

\section{c. Uji Hipotesis}

\section{1) Uji Signifikansi Parsial (Uji t)}

Uji t bertujuan untuk melihat secara parsial apakah ada pengaruhyang signifikan dari variabel bebas $(\mathrm{X})$ terhadap variabel terikat $(\mathrm{Y})$.Bentukpengujiannya :

- $\mathrm{H}_{0}$ : bi $=0$, artinya secara parsial produk $\left(\mathrm{X}_{1}\right)$, harga $\left(\mathrm{X}_{2}\right)$, lokasi $\left(\mathrm{X}_{3}\right)$, dan promosi $\left(\mathrm{X}_{4}\right)$ tidak berpengaruhsignifikan terhadap keputusan berkunjung $(\mathrm{Y})$.

- $\mathrm{H}_{\mathrm{a}}$ : bi $\neq 0$, artinya secara parsial produk $\left(\mathrm{X}_{1}\right)$, harga $\left(\mathrm{X}_{2}\right)$, lokasi $\left(\mathrm{X}_{3}\right)$, dan promosi $\left(\mathrm{X}_{4}\right)$ tidak berpengaruhsignifikan terhadap keputusan berkunjung (Y).

Nilai thitung akan dibandingkan dengan nilai $t_{\text {tabel. }}$ Kriteriapengambilankeputusan yaitu :

- $\mathrm{H}_{0}$ diterima apabila nilai thitung $<\mathrm{t}_{\text {tabel }}$ pada $\alpha=5 \%$.

- $\mathrm{H}_{\mathrm{a}}$ diterima apabila nilai $\mathrm{t}_{\text {hitung }}>\mathrm{t}_{\text {tabel }}$ pada $\alpha=5 \%$.

\section{2) Uji Signifikansi Simultan (Uji F)}

Uji $F$ disebut juga uji serempak yaitu seberapa besar pengaruh variabel bebas $\left(\mathrm{X}_{1}, \mathrm{X}_{2}, \mathrm{X}_{3}\right.$, dan $\mathrm{X}_{4}$ ) secara serempak terhadap variabel terikat (Y). Uji Fdalam penelitian ini bertujuan untuk melihat apakah variabel produk $\left(\mathrm{X}_{1}\right)$, harga $\left(\mathrm{X}_{2}\right)$, lokasi $\left(\mathrm{X}_{3}\right)$, dan promosi $\left(\mathrm{X}_{4}\right)$ secara serempak (simultan) berpengaruh signifikan terhadap keputusan berkunjung (Y). Bentuk pengujiannya adalah :

- $\mathrm{H}_{0}: \mathrm{b}_{1}=\mathrm{b}_{2}=\mathrm{b}_{3}=\mathrm{b}_{4}=0$, artinya secara serempakproduk $\left(\mathrm{X}_{1}\right)$, harga $\left(\mathrm{X}_{2}\right)$, lokasi $\left(\mathrm{X}_{3}\right)$, dan promosi $\left(\mathrm{X}_{4}\right)$ tidak berpengaruhsignifikan terhadap keputusan berkunjung $(\mathrm{Y})$. 
- Ha : $b_{1} \neq b_{2} \neq b_{3} \neq b_{4} \neq 0$, artinya secara serempakproduk $\left(X_{1}\right)$, harga $\left(X_{2}\right)$, lokasi $\left(X_{3}\right)$, dan promosi $\left(\mathrm{X}_{4}\right)$ berpengaruhsignifikan terhadap keputusan berkunjung $(\mathrm{Y})$.

Nilai $F_{\text {hitung }}$ akan dibandingkan dengan nilai $\mathrm{F}_{\text {tabel. }}$ Kriteriapengambilan keputusan yaitu :

- $\mathrm{H}_{0}$ diterima apabila nilai $\mathrm{F}_{\text {hitung }}<\mathrm{F}_{\text {tabel }}$, pada $\alpha=5 \%$.

- $\mathrm{H}_{\mathrm{a}}$ diterima apabila nilai $\mathrm{F}_{\text {hitung }}>\mathrm{F}_{\text {tabel, }}$, pada $\alpha=5 \%$.

3) Koefisien Determinasi $\left(\boldsymbol{R}^{2}\right)$

Identifikasi determinan $\left(R^{2}\right)$ berfungsi untuk mengetahui signifikansivariabel maka harus dicari koefisien determinasi $\left(R^{2}\right)$. Koefisiendeterminan menunujukkan besarnya kontribusi variabel independen terhadap variabeldependen. Semakin besar nilai koefisien determinasi, maka semakin baikkemampuan variabel independen menerangkan variabel dependen. Jikadeterminasi $\left(R^{2}\right)$ semakin besar (mendekati satu), maka dapat dikatakan bahwapengaruh variabel independen adalah besar terhadap variabel dependen. Hal iniberarti, model yang digunakan semakin kuat untuk menerangkan pengaruhvariabel independen yang diteliti terhadap variabel dependen.

\section{HASIL DAN PEMBAHASAN}

\section{A. Uji Asumsi Klasik}

a. Uji Normalitas

Untuk melihat normalitas residual penulis menganalisis grafik histogram yang membandingkan antara data observasi dengan distribusiyang mendekati distribusi normal dan juga menganalisis probality plot yang membandingkan distribusi kumulatif dari distribusi normal. Jika data menyebar disekitar garis diagonal dan mengikuti arah garis diagonal atau grafik histogram menunjukkan pola distribusi normal, maka model regresi memenuhi asumsi klasik. Jika data menyebar jauh dari garis diagonal dan atau tidak mengikuti arah garis diagonal atau grafik histogram menunjukkan pola distribusi normal, maka model regresi tidak memenuhi asumsi klasik.

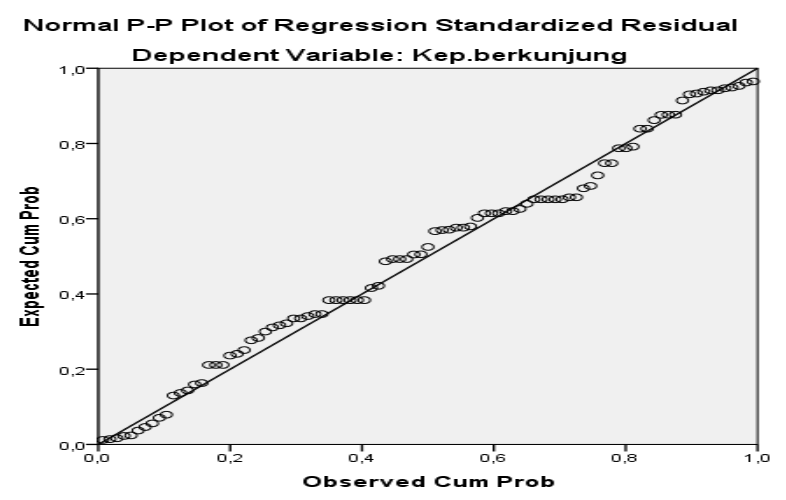

Gambar1Grafik Normal P-PPlot

Pada gambar dapat dilihat bahwa data (titik-titik) menyebar di sekitar garis diagonal dan mengikuti garis diagonal.Oleh karena itu, berdasarkan gambar maka dapat diambil kesimpulan bahwa data terdistribusi normal.

Untuk memastikan apakah data disepanjang garis diagonal berdistribusi normal maka dilakukan uji Kolmogorv Smirnov dengan melihat data residual apakah berdistribusi normal (Situmorang, et al 59:2008). Jika nilai Asymp.Sig. (2-tailed)> 0,05 maka tidak mengalami gangguan distribusi normal, jika nilai Asymp.Sig (2-tailed) $<0,05$ maka mengalami gangguan distribusi normal. 
Tabel 1

Hasil Uji Normalitas PendekatanKolmogorov-Smirnov One-Sample Kolmogorov-Smirnov Test

\begin{tabular}{|c|c|c|}
\hline & & $\begin{array}{c}\text { Unstandardized } \\
\text { Residual }\end{array}$ \\
\hline $\begin{array}{l}\text { N } \\
\text { Normal Parameters }{ }^{a, b} \\
\text { Most Extreme Differences } \\
\text { Kolmogorov-Smirnov Z } \\
\text { Asymp. Sig. (2-tailed) }\end{array}$ & $\begin{array}{l}\text { Mean } \\
\text { Std. Deviation } \\
\text { Absolute } \\
\text { Positive } \\
\text { Negative }\end{array}$ & $\begin{array}{r}93 \\
0 \mathrm{E}-7 \\
, 67284335 \\
, 071 \\
, 071 \\
-, 063 \\
, 683 \\
, 739 \\
\end{array}$ \\
\hline
\end{tabular}

a. Test distribution is Normal.

b. Calculated from data.

Tabel di atas terlihat bahwa Asymp.Sig (2-tailed) adalah 0,739 dan diatas nilai signifikan $(0,05)$, dengan kata lain variabel residualberdistribusi normal.

\section{b. Uji Multikolinearitas}

Uji Multikolinearitas bertujuan untuk menguji adanya korelasi antara variabel independen. Jika terjadi korelasi maka dinamakan multikol, yaitu adanya masalah multikolinearitas. Model regresi yang baik seharusnya tidak terjadi korelasi antara variabel independen. Hasil pengolahan dapat dilihat pada tabel sebagai berikut :

Tabel 2

Hasil Uji Multikolinearitas Coefficients $^{\mathrm{a}}$

\begin{tabular}{|c|c|c|c|c|c|c|c|}
\hline \multirow[t]{2}{*}{ Model } & \multicolumn{2}{|c|}{$\begin{array}{c}\text { Unstandardized } \\
\text { Coefficients }\end{array}$} & $\begin{array}{c}\text { Standardized } \\
\text { Coefficients }\end{array}$ & \multirow[t]{2}{*}{$\mathrm{t}$} & \multirow[t]{2}{*}{ Sig. } & \multicolumn{2}{|c|}{ Collinearity Statistics } \\
\hline & $\mathrm{B}$ & Std. Error & Beta & & & Tolerance & VIF \\
\hline (Constant) &,- 239 & 1,253 & &,- 191 & ,849 & & \\
\hline Produk & ,281 & 084 & ,297 & 3,321 &, 001 &, 572 & 1,750 \\
\hline Harga & , 482 & ,090 & ,430 & 5,350 &, 000 & ,705 & 1,418 \\
\hline Lokasi & 191 & ,088 & 189 & 2,177 & ,032 & 602 & 1,661 \\
\hline Promosi & 068 & ,085 & 056 & ,794 & ,429 & ,908 & 1,102 \\
\hline
\end{tabular}

Berdasarkan Tabel diatas menunjukkan bahwa nilai Tolerance variabelindependen $>$ 0,1 dan nilai VIF variabel independen $<5$, maka dapatdisimpulkan bahwa regresi tidak terkena multikolinearitas.

\section{c. Uji Heteroskedostisitas}

Uji Heteroskedastisitas bertujuan untuk menguji apakah dalamsuatumodel regresi terjadi ketidaksamaan varians dari residual pada satupengamatanke pengamatan yan g lainnya tetap, maka disebuthomoskedastisitas. Model regresiyang baik adalah tidak terjadiheteroskedastisitas.

Deteksi ada tidaknya gejala heteroskedastisitas adalah dengan melihat adatidaknya pola tertentu pada grafik Scaterplot di sekitar nilai $\mathrm{X}_{1}, \mathrm{X}_{2}, \mathrm{X}_{3}, \mathrm{X}_{4}$ danY. Jika ada pola tertentu, maka telah terjadi gejala heteroskedastisitas. 


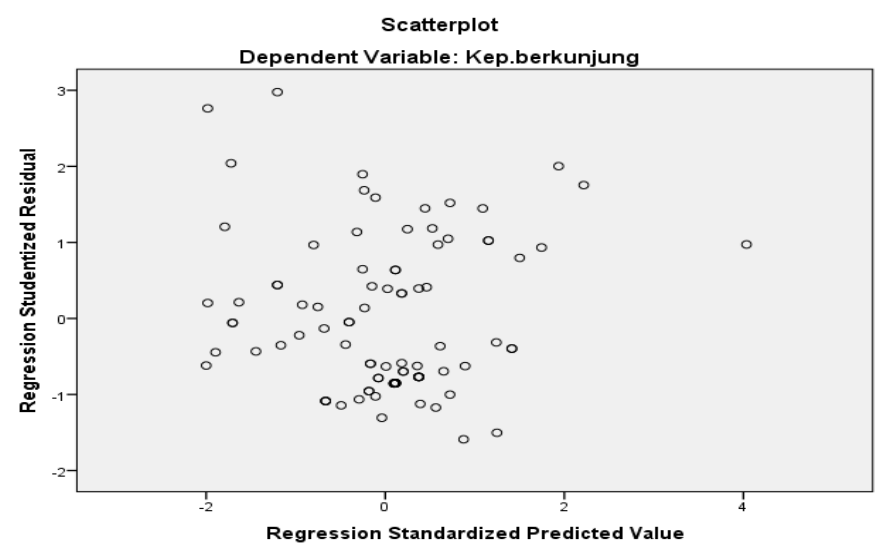

Gambar2Scatterplot

Gambar grafik scatterplot terlihat titik-titik menyebar secaraacak dantidak membentuk sebuah pola tertentu yang jelas, serta tersebarbaik di atasmaupun dibawah angkat 0 pada sumbu Y. Hal ini berarti tidakterjadi heteroskedastisitas pada model regresi.

Untuk lebih menguatkan hasil uji secara grafik, dapat dilakukan Uji Glejserdengan cara me-regres nilai absolut residual terhadapvariabelindependen.

Tabel 3

Hasil Uji Glejser

Coefficients $^{\mathrm{a}}$

\begin{tabular}{|ll|r|r|r|r|r|}
\hline Model & \multicolumn{2}{|c|}{ Unstandardized Coefficients } & \multicolumn{1}{c|}{$\begin{array}{c}\text { Standardized } \\
\text { Coefficients }\end{array}$} & \multicolumn{1}{c|}{ Sig. } \\
\cline { 3 - 5 } & \multicolumn{1}{|c|}{$\mathrm{B}$} & \multicolumn{1}{c|}{ Std. Error } & \multicolumn{1}{c|}{ Beta } & \\
\hline \multirow{2}{*}{1 (Constant) } & 1,383 &, 733 & & 1,886 &, 063 \\
& Produk &,- 129 &, 049 &,- 352 & $-2,619$ &, 110 \\
& Harga &,- 011 &, 053 &,- 025 &,- 208 &, 836 \\
& Lokasi &, 097 &, 051 &, 247 & 1,888 &, 062 \\
& Promosi &,- 035 &, 050 &,- 074 &,- 695 &, 489 \\
\hline
\end{tabular}

a. Dependent Variable: AbsRes

Dari Tabel di atas dapat dilihat bahwa signifikansi variabel independen lebih besar dari 0,05.Dengan demikian tidak terjadi gangguan heteroskedastisitas dalam model regresi.

\section{B. Analisis Regresi Linear Berganda}

Analisis regresi linear berganda digunakan untuk mengetahui berapa besar pengaruh variabel bebas $\left(\mathrm{X}_{1}, \mathrm{X}_{2}, \mathrm{X}_{3}\right.$, dan $\left.\mathrm{X}_{4}\right)$ terhadap variabel terikat $(\mathrm{Y})$. Maka untuk memperoleh hasil yang lebih akurat digunakan program software SPSS 20.0 for windows, makadari Tabel coefficient dihasilkan output sebagai berikut :

Tabel 4

Hasil Regresi Linear Berganda Coefficients $^{\mathrm{a}}$

\begin{tabular}{|c|c|c|c|c|c|c|}
\hline \multirow[t]{2}{*}{ Mod } & & \multicolumn{2}{|c|}{ Unstandardized Coefficients } & \multirow{2}{*}{$\begin{array}{c}\text { Standardized } \\
\text { Coefficients } \\
\text { Beta }\end{array}$} & \multirow[t]{2}{*}{$\mathrm{t}$} & \multirow[t]{2}{*}{ Sig. } \\
\hline & & $\mathrm{B}$ & Std. Error & & & \\
\hline \multirow{5}{*}{1} & (Constant) &,- 239 & 1,253 & &,- 191 & 849 \\
\hline & Produk & ,281 & ,084 & ,297 & 3,321 & ,001 \\
\hline & Harga & ,482 & 090 & , 430 & 5,350 &, 000 \\
\hline & Lokasi & ,191 & ,088 & ,189 & 2,177 & ,032 \\
\hline & Promosi & ,068 & 085 & ,056 & ,794 & ,429 \\
\hline
\end{tabular}

a. Dependent Variable: Kep.berkunjung 
Berdasarkan hasil pengolahan data seperti terlihat pada Tabel KolomUnstandardized Coefficients bagian B nilai koefien regresi masing-masing variabel, yaitu :

1) Konstanta (a) = -0,239. Ini berarti bahwa apabila variabel produk,harga, lokasi, dan promositidak ada, maka keputusan berkunjung ke Wisata Alam Waterboom Desa Janji sebesar -0,239.

2) Koefisien $X_{1}\left(b_{1}\right)=0,281$. Ini berarti bahwa jika variabel produk ditingkatkan sebesar satu satuan dan variabel lainnya dianggap konstan, maka keputusan berkunjung ke Wisata Alam Waterboom Desa Janjiakan meningkat sebesar 0,281.

3) Koefisien $X_{2}\left(b_{2}\right)=0,482$. Ini berarti bahwa jika variabel harga ditingkatkan sebesar satu satuan dan variabel lainnya dianggap konstan, maka keputusan berkunjung ke Wisata Alam Waterboom Desa Janjiakan meningkat sebesar 0,482.

4) Koefisien $X_{3}\left(b_{3}\right)=0$,191. Ini berarti bahwa jika variabel lokasi ditingkatkan sebesar satu satuan dan variabel lainnya dianggap konstan, maka keputusan berkunjung ke Wisata Alam Waterboom Desa Janjiakan meningkat sebesar 0,191.

5) Koefisien $X_{4}\left(b_{4}\right)=0,068$.Ini berarti bahwa jika variabel promosi ditingkatkan sebesar satu satuan dan variabel lainnya dianggap konstan, maka keputusan berkunjung ke Wisata Alam Waterboom Desa Janjiakan meningkat sebesar 0,068.

Berdasarkan hasil tersebut, maka persamaan regresi adalah :

$Y=-0,239+0,281 X_{1}+0,482 X_{2}+0,191 X_{3}+0,068 X_{4}+e$

\section{Pengujian Hipotesis}

Hipotesis pada penelitian ini diuji dengan menggunakan uji signifikansi parsial (Uji t), uji signifikansi simultan (Uji F), dan koefisien determinasi $\left(R^{2}\right)$.

\section{a. Uji Signifikansi Parsial (Uji t)}

Nilai thitung diperoleh dari pengolahan data SPSS 20.0 for Windows, kemudian akan

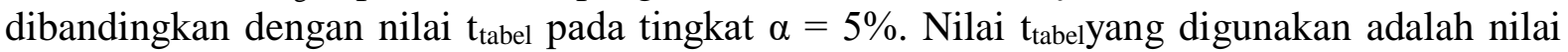
distribusi $\mathrm{t}$ dengan derajat bebas $(\mathrm{df})$ yaitu $(\mathrm{df} 1)=\mathrm{k}-1=5-1=4$, dan $(\mathrm{df} 2)=\mathrm{n}-\mathrm{k}=93-5=$ 88. Uji thitung yang dilakukan adalah uji dua arah maka $t_{\text {tabel }}$ yang digunakan adalah $\mathrm{t} 5 \%$ atau $\mathrm{t}_{0,05}(88)=1,66235$.

Tabel 5

Hasil Uji Parsial (Uji t) Coefficients $^{\mathrm{a}}$

\begin{tabular}{|c|c|c|c|c|c|c|}
\hline \multirow{2}{*}{\multicolumn{2}{|c|}{ Model }} & \multicolumn{2}{|c|}{ Unstandardized Coefficients } & Standardized & \multirow[t]{2}{*}{$\mathrm{t}$} & \multirow[t]{2}{*}{ Sig. } \\
\hline & & $\mathrm{B}$ & Std. Error & Beta & & \\
\hline \multirow{5}{*}{1} & (Constant) &,- 239 & 1,253 & &,- 191 & ,849 \\
\hline & Produk & ,281 & 084 & ,297 & 3,321 & 001 \\
\hline & Harga & ,482 & ,090 & ,430 & 5,350 & , 000 \\
\hline & Lokasi & ,191 & ,088 & , 189 & 2,177 & ,032 \\
\hline & Promosi & ,068 & ,085 & ,056 & ,794 & ,429 \\
\hline
\end{tabular}

a. Dependent Variable: Kep.berkunjung

Berdasarkan Tabel diatas, maka dapat dijelaskan sebagai berikut :

1) Hasil uji $t$ untuk variabel produk $\left(X_{1}\right)$ diperoleh nilai $t_{\text {hitung }}(3,321)>t_{\text {tabel }}(1,66235)$ dengan taraf signifikansi 0,001 $<0,05$. Hasil ini menunjukkan bahwa produk berpengaruh positif dan signifikan terhadap keputusan berkunjung ke Wisata Alam Waterboom Desa Janji. Dengan demikian hipotesis dapat diterima.

2) Hasil uji $t$ untuk variabel harga $\left(X_{2}\right)$ diperoleh nilai $t_{\text {hitung }}(5,350)>t_{\text {tabel }}(1,66235)$ dengan taraf signifikansi $0,000<0,05$. Hasil ini menunjukkan bahwa hargaberpengaruh positif dan signifikan terhadap keputusan berkunjung ke Wisata Alam Waterboom Desa Janji. Dengan demikian hipotesis dapat diterima. 
3) Hasil uji t untuk variabel lokasi $\left(X_{3}\right)$,diperoleh nilai $t_{\text {hitung }}(2,177)>t_{\text {tabel }}(1,66235)$ dengan taraf signifikansi $0,032<0,05$. Hasil ini menunjukkan bahwa lokasi berpengaruh positif dan signifikan terhadap keputusan berkunjung ke Wisata Alam Waterboom Desa Janji. Dengan demikian hipotesis diterima.

4) Hasil uji t untuk variabel promosi $\left(X_{4}\right)$,diperoleh nilai $t_{\text {hitung }}(0,794)<t_{\text {tabel }}(1,66235)$ dengan taraf signifikansi 0,429>0,05. Hasil ini menunjukkan bahwa promosi berpengaruh positif dan tidak signifikan terhadap keputusan berkunjung ke Wisata Alam Waterboom Desa Janji. Dengan demikian hipotesis ditolak.

b. Uji Signifikansi Simultan (Uji F)

Nilai $F_{\text {hitung }}$ diperoleh dari pengolahan data SPSS 20.0 for Windows, kemudian akan dibandingkan dengan nilai $F_{\text {tabel }}$ pada tingkat $\alpha=5 \%$. Nilai $F_{\text {tabelyang digunakan adalah nilai }}$ distribusi $\mathrm{F}$ dengan derajat bebas (df),yaitu df1 $=5-1=4$, dan df $2=93-5=88$. Maka $\mathrm{F}_{\text {tabel }}$ yang digunakan adalah nilai $\mathrm{F}(4: 88)=2,48$.

\section{Tabel 6}

Hasil Uji Simultan (Uji F)

ANOVA $^{\mathrm{a}}$

\begin{tabular}{|ll|r|r|r|r|r|}
\hline Model & & Sum of Squares & df & Mean Square & F & Sig. \\
\hline \multirow{4}{*}{1} & Regression & 62,156 & 4 & 15,539 & 32,832 &, $000^{\mathrm{b}}$ \\
& Residual & 41,650 & 88 &, 473 & & \\
& Total & 103,806 & 92 & & & \\
\hline
\end{tabular}

a. Dependent Variable: Kep.berkunjung

b. Predictors: (Constant), Promosi, Produk, Harga, Lokasi

Berdasarkan Tabel diatasdapat diketahui bahwa nilai $F_{\text {hitung }}(32,832)>F_{\text {tabel }}$ $(2,48)$ dengan taraf signifikansi $0,000<0,05$. Hasil ini menunjukkan bahwa secara serempak (bersama-sama) produk $\left(\mathrm{X}_{1}\right)$, harga $\left(\mathrm{X}_{2}\right)$, lokasi $\left(\mathrm{X}_{3}\right)$, dan promosi $\left(\mathrm{X}_{4}\right)$ berpengaruh positif dan signifikanterhadap keputusan berkunjung ke Wisata Alam Waterboom Desa Janji (Y). Dengan demikian hipotesis dapat diterima.

c. Koefisien Determinasi $\left(\boldsymbol{R}^{2}\right)$

Hasil pengujian koefisien determinasi menggunakan program SPSSStatistik 20.0 for windows dapat terlihat pada tabel sebagai berikut :

\section{Tabel 7}

Koefisien Determinasi Model Summary

\begin{tabular}{|l|r|r|r|r|}
\hline Model & $\mathrm{R}$ & $\mathrm{R}$ Square & $\begin{array}{c}\text { Adjusted R } \\
\text { Square }\end{array}$ & $\begin{array}{c}\text { Std. Error of the } \\
\text { Estimate }\end{array}$ \\
\hline 1 &, $774^{\mathrm{a}}$ &, 599 & \multicolumn{3}{|c|}{, 581} &, 688 \\
\hline
\end{tabular}

Berdasarkan Tabel 4.13 dapat dijelaskan sebagai berikut :

1) Nilai $R$ sebesar 0,774 berarti produk, harga, lokasi, dan promosi terhadap keputusan berkunjung ke Wisata Alam Waterboom Desa Janji sebesar 77,4\% artinya hubungannyaerat.

2) Nilai AdjustedR Square sebesar 0,581 berarti sebesar $58,1 \%$ keputusan berkunjung ke Wisata Alam Waterboom Desa Janji dapat dijelaskan olehproduk, harga, lokasi, danpromosi sedangkan sisanya dapat dijelaskan oleh variabel lain.

3) Standar error of estimate (standar deviasi) artinya hasil penelitianmenunjukkan standard error of estimated adalah 0,688

\section{Pembahasan}

Penelitian ini bertujuan untuk mengetahui pengaruhProduk, Harga, Lokasi dan Promosi terhadap Keputusan Berkunjung ke Wisata Alam Waterboom Desa Janji. Penelitian inidilakukan dengan menggunaan metode analisis deskriptif dan metode analisisregresi berganda, dengan menggunakan uji signifikan simultan (uji F), uji signifikan parsial (uji t) 
dan koefisien determinasi $\left(R^{2}\right)$. Pada metode analisisdeskriptif diperoleh informasi dari responden melalui kuesioner yang berisikantentang karakteristik responden yaitu jenis kelamin, usia, dan jawaban respondenatas pertanyaan dalam kuesioner. Sedangkan pada metode analisis regresiberganda dan pengujian hipotesis, pengolahan data dilakukan dengan aplikasisoftware SPSS 20.0 for windows.

Berdasarkan hasil uji $\mathrm{F}$ maka diperoleh nilai $\mathrm{F}_{\text {hitung }}=32,832$. Hal inimenunjukkan bahwa nilai $F_{\text {hitung }}>F_{\text {tabel }}$ yaitu 32,832 > 2,48 dengan demikianhipotesis Ho ditolak dan $\mathrm{Ha}$ diterima. Artinya secara bersama-sama (serempak)variabel independen (Produk, Harga, Lokasi, Promosi) berpengaruh positif dan signifikan terhadap keputusan berkunjung ke Wisata Alam Waterboom Desa Janji.Salah satu cara untuk dapat merebut hati pengunjung agar tertarik untukberkunjung adalah dengan cara menerapkan strategi pemasaran yang salah satuelemennya adalah dengan bauran pemasaran. Bauran Pemasaran adalah kumpulanalat pemasaran taktis terkendali yang dipadukan perusahaan untuk menghasilkanrespons yang diinginkan di pasar sasaran (Kotler dan Amstrong,2008:62). Bauranpemasaran terdiri dari semua hal yang dapat dilakukan perusahaan untukmempengaruhi permintaan produknya. Berbagai kemungkinan ini dapatdikelompokkan menjadi empat kelompok variabel yang disebut "4P":Product, Price, Place dan Promotion. Faktor produk, harga, lokasi dan promosiadalah merupakan faktor penting di dalam bauran pemasaran.Demikian halnyadalam penerapan strategi yang dilakukan oleh perusahaan jasa di dalam jugasenantiasa menerapkan pengembangan daripada strategi harga, lokasi dan promosiyang tepat agar dapat menarik minat konsumen untuk berkunjung ke daerahwisata tersebut.

Berdasarkan hasil uji t maka dapat diperoleh variabel produkberpengaruh positif dan signifikan terhadap keputusan berkunjung ke Wisata Alam Waterboom Desa Janji. Hal initerlihat dari nilai signifikan produk yaitu $0,001<0,05$, dan nilai thitung $(3,321)>$ nilai $t_{\text {tabel }}$ $(1,66235)$ artinya jika ditingkatkan produksebesar satu satuan maka keputusan berkunjung ke Wisata Alam Waterboom Desa Janji akan meningkat sebesar0,281. Produk berarti kombinasi barang dan jasa yang ditawarkan perusahaankepada pasar sasaran (Yoeti,2007: 29). Apa keunikan produk yang kita tawarkan,siapa pasar sasaran utama jasa kita, kemudian apakah produk tersebut akanmampu bertahan dan untuk berapa lama produk tersebut dapat bertahan.

Variabel harga berpengaruhpositif dan signifikanterhadap keputusan berkunjung ke Wisata Alam Waterboom Desa Janji. Hal ini terlihat darinilai signifikan hargayaitu 0,000< 0,05 , dan nilai $t_{\text {hitung }}(5,350)>$ nilai $t_{\text {tabel }}(1,66235)$ artinya jikaditingkatkan harga sebesar satu satuan maka keputusan berkunjung ke Wisata Alam Waterboom Desa Janji akan meningkat sebesar 0,482. Hargaadalah merupakan sesuatu yang diserahkan dalam pertukaran untuk mendapatkansuatu barang atau jasa (Lamb, dkk. 2008:268). Faktor harga sangat mempengaruhiterhadap keputusan pembelian. Waterboom Desa Janji memberikan penawaranharga yang relatif terjangkau untuk harga tiket masuk ke lokasi tempat wisata,adanya potongan harga yang diberikan sehingga membuat konsumen tertarikuntuk berkunjung.

Variabel lokasi berpengaruh positif dansignifikan terhadap keputusan berkunjung ke Wisata Alam Waterboom Desa Janji. Hal ini terlihat dari nilai signifikanlokasi yaitu 0,032< 0,05 , dan nilai $t_{\text {hitung }}(2,177)>$ nilai $t_{\text {tabel }}(1,66235)$ artinya jikaditingkatkan lokasi sebesar satu satuan maka keputusan berkunjung ke Wisata Alam Waterboom Desa Janji akanmeningkat sebesar 0,191. Lokasi adalah suatu wilayah atau tempat dimana perusahaandapat menjalankan atau melaksanakan kegiatan pemasarannya kepada masyarakat(Yoeti, 2007:32). Lokasi tempat wisata yang nyaman, aman, bersih, ramai, danmudah dijangkau, merupakan beberapa kriteria lokasi yang diminati oleh banyakkonsumen.

Variabel promosi berpengaruh positif dan tidak signifikanterhadap keputusan berkunjung ke Wisata Alam Waterboom Desa Janji. Hal ini terlihat dari nilai signifikan promosiyaitu $0,429>0,05$, dan nilai thitung $(0,794)<$ nilai $t_{\text {tabel }}(1,66235)$ artinya 
jikaditingkatkan promosi sebesar satu satuan maka keputusan berkunjung ke Wisata Alam Waterboom Desa Janji akanmeningkat sebesar 0,068.Promosi merupakan salah satu kegiatan pemasaran yang penting bagiperusahaan dalam upaya mempertahankan kontinuitas serta meningkatkaankualitas penjualan untuk meningkatkan kegiatan pemasaran dalam halmemasarkan barang atau jasa dari suatu perusahaan (Lovelock, 2009: 20).Padaumumnya perusahaan melakukan promosi agar para konsumen tertarik untukmengunjungi tempat wisata tersebut. Waterboom Desa Janji telah mendesainpromosi seperti dengan memasang iklan, membagikan undian berhadiah dengantarget utama adalah masyarakat sekitar.Berdasarkan hasil pengujian koefisien determinan $\left(R^{2}\right)$ maka Nilai Adjusted $R$ Square0,581 berarti sebesar 58,1\% keputusan berkunjung ke Wisata Alam Waterboom Desa Janji dapat dijelaskan oleh produk, harga, lokasi, dan promosisedangkan sisanya dapat dijelaskan oleh variabel lain.

\section{DAFTAR PUSTAKA}

Antony, Julius dan Jolanda. 2009. "Faktor-Faktor Yang Mempengaruhi Keputusan Konsumen Dalam Memilih Starbucks Coffee di Galaxy Mall”. Jurnal.Surabaya : Universitas Krosten Petra.

Churchill, Gilbert A. Jr. 2009. Riset Pemasaran. Jilid I, Edisi kedelapan. Terjemahan Dr. Dwi Kartini Yahya S.E. M.M. Jakarta : Erlangga.

Fure, Hendra. 2013. "Lokasi, Keberagaman Produk, Harga, dan Kualitas Pelayanan Serta Pengaruhnya Terhadap Minat Beli Pada Pasar Tradisional Bersehatii Calaca". Jurnal Fakultas Ekonomi dan Bisnis.Manado : Universitas Sam Ratulangi.

Kotler, Philip dan Gary Armstrong. 2008. Prinsip-prinsip Pemasaran. Jilid I, Edisi Kedelapan. Jakarta: Erlangga.

Kotler, Philip dan Kevin Lane Keller. 2007. Manajemen Pemasaran. Jilid 1, Edisi Kedua Belas. Jakarta : PT Indeks.

Kuncoro, Mudrajad. 2009. Metode Riset untuk Bisnis \& Ekonomi (Edisi 3).Jakarta : Erlangga.

Lamb, Charles W. Jr., Joseph F. Hair, Jr., dan Carl McDaniel. 2008. Pemasaran. Buku 2. Terjemahan David Octarevia. Jakarta : Salemba Empat.

Lovelock. 2009. Manajemen Pemasaran Jasa. Jilid I, Edisi keenam.Jakarta : PT. Indeks.

Machfoedz, Mahmud. 2007. Pengantar Bisnis Modern. Yogyakarta : Andi Publisher.

Scarborough, Zimmer. 2008. Kewirausahaan dan Manajemen Usaha Kecil. Jilid I, Edisi ketiga.Jakarta : Salemba Empat.

Siburian, Cempaka Kezia. 2013. "Pengaruh Produk, Lokasi, Harga, dan Promosi Terhadap Minat Berkunjung Kembali ke Tempat Wisata Draco Waterpark Hermes Medan”. Jurnal FEB.Medan : USU.

Situmorang, Syafrizal Helmi, Doli M. Ja'far Dalimunthe, Iskandar Muda, Muslich Lufti, Syahyunan. 2008. Analisis Data Penelitian. Terbitan Pertama. Medan : USU Press.

Sugiyono. 2008. Metode Penelitian Bisnis. Cetakan kelima.Bandung : Alfabeta.

Sunarto. 2006. Prinsip-prinsip Pemasaran. Yogyakarta : AMUS dan UST Press.

Suwantoro, Gamal. 2007. Dasar-Dasar Pariwisata. Yogyakarta : Andi Publisher.

Tjiptono, Fandy. 2008. Pemasaran Jasa. Edisi I. Malang : Bayumedia Pubishing.

Umar, Husein. 2006. Riset Pemasaran dan Perilaku Konsemen.Jakarta : Gramedia Pustaka Utama.

Usman, Hardius dan Nurdin Sobari. 2013. Aplikasi Teknik Multivariate untuk Riset Pemasaran. Jakarta : PT. Raja Grafindo Persada.

Winardi. 2010. Manajemen Perilaku Organisasi. Jakarta : Prenada Media.

Yoeti, H. Oka A. 2005. Pemasaran Pariwisata. Jakarta : Gramedia Pustaka Utama. 2007. Strategi Pemasaran. Jakarta : Gramedia Pustaka Utama. 